\title{
School Sport and Academic Harvest
}

\author{
Jun Chen ${ }^{1, a^{*}}$ and Yiting Chen ${ }^{2, b}$ \\ Southwest Petroleum University, Cheng Du \\ A626452076@qq.com, b416304926@qq.com \\ * The Corresponding Author
}

Keywords: Physical fitness and sport; Academic achievement; Team sports; Individual sports

\begin{abstract}
Background: Physical Education and School Sport (PESS) is an integral part of the school curriculum in Ireland. Historically the "Healthy Body, Healthy Mind", philosophy has promoted the inclusion of PESS alongside more cognitive school subjects. Research suggests that PESS can promote cognitive function and provide educational benefits. However, there is little research on how the choice of school sport influences academic achievement. This study investigated how participation in school sport influences the Leaving Certificate points score in an Irish secondary school. In particular, the study will investigate how the particular sport chosen by students participating in school sport during their Leaving Certificate years influences their Leaving Certificate results. Methods: We recorded the Leaving Certificate scores and sports participation from 402 boys graduating from a secondary school in the Ireland during 2008-2011. Sports participation was assigned 1 of 4 categories: rugby, rowing, soccer, and no sport. Results: Participation in sports during the Leaving Certificate years conferred a 25.4-point benefit to the final Leaving Certificate score. However, participation in rowing, the only individual sport available in the study, resulted in significantly higher Leaving Certificate scores than rugby, soccer and no sport ( $\mathrm{p}<.05$ ), conferring an additional 73.4-point benefit over the next highest group, rugby. Conclusion: Promoting participation in school sport and providing access to a range of team and individual sports throughout the secondary school years may be a beneficial way to improve students' Leaving Certificate results.
\end{abstract}

Physical Education and School Sport (PESS) has Phistorically been considered an integral and essential part of childhood, promoting a range of benefits including childhood health, cognitive development, motor skills, and prosocial behavior.1-3 The positive influence of sport and exercise on health is well recognized.4 In Ireland, the current generation of young adults played two thirds more sport when they were children than their parents did when they were children.5 Despite this only $12 \%$ of current post primary children meet the Department of Health and Children physical activity recommendations of at least 60 minutes/day of moderate to vigorous physical activity and the average time spent in school Physical Education is only 77 minutes/week. 6 The number of individuals who are overweight or obese in Ireland is increasing7 and Ireland has one of the highest prevalence of overweight children in comparison to other European and developed countries8 with 1 in 4 Irish children either unfit, overweight, obese, or having high blood pressure.6 Physical Education and School Sport is also viewed as beneficial to educational attainment.1 Several studies have shown that increasing the time devoted to PESS did not harm academic achievement and may enhance achievement in some subjects despite the reduction in teaching time.9,10 However, results can be conflicting and further research seems to be necessary to define the precise relationship between PESS and cognitive outcomes. 1 However, there are many aspects of PE that can be included in PESS and many sports and activities can be used. Schools in Ireland offer a wide range of sports, but individual schools often limit focus to a few, prioritized sports aligned with dedicated coaches/PE staff. Weekly physical activity levels are greatest in primary school children (10-12 years). This then declines with age in both children and adults.6, 11

Physical Education and School Sport in Ireland has been the subject of several recent studies and a new syllabus is currently being prepared for the Senior Cycle Curriculum. ${ }^{6,12,13}$ In Ireland, 76\% of adult sport is individual sport, with the most popular sports being aerobics/keep fit, swimming, golf, jogging, 
and cycling. ${ }^{5}$ In contrast, team games occupy the most popular school sports with basketball being the most popular, followed by soccer, rounders, then badminton. ${ }^{6}$ However, there is little research quantifying how participating in a particular sport influences academic achievement. This study is a first investigation of the relationship between choice of school sports and educational achievement at 1 school in Ireland.

\section{Methods}

\section{Participants}

The Leaving Certificate results (the Irish State School Examination) were analyzed from 402 stu-dents (age 17-18 years) graduating from an all-boys secondary school between 2014 and 2017.

\section{Procedure}

Most students completed 7 exam subjects with some doing an "extra" subject such as music. On comple-tion of the Leaving Certificate examinations, the 6 best subjects are allocated points on a sliding scale as shown in Table 1. Students can achieve a maximum of 600 points and these points are used to apply for third level courses.

The student's Leaving Certificate scores were divided into 1 of 4 categories based on their sporting participation. The main sports at the school in the current study were rugby, soccer, and rowing. During the 2 years studying for the Leaving Certificate, these sports were available as extracurricular activities only, that is, they were not timetabled in the normal curriculum and students participating in these sports would do so in addition to their normal timetabled classes. The sports participation of each school child was assessed according to 4 categories: rugby, rowing, soccer, and no sport.

\begin{tabular}{cccc}
\hline & \multicolumn{3}{c}{ Table 1. Irish Leaving Certificate Examination Poin } \\
\cline { 2 - 4 } & $\begin{array}{c}\text { Leaving Certificate } \\
\text { Grade }\end{array}$ & $\begin{array}{l}\text { Higher } \\
\text { Paper }\end{array}$ & $\begin{array}{l}\text { Lower } \\
\text { Paper }\end{array}$ \\
\hline A1 & 100 & 60 \\
A2 & 90 & 50 \\
B1 & 85 & 45 \\
B2 & 80 & 40 \\
B3 & 75 & 35 \\
C1 & 70 & 30 \\
C2 & 65 & 25 \\
C3 & 60 & 20 \\
D1 & 55 & 15 \\
D2 & 50 & 10 \\
D3 & 45 & 5 \\
& & \\
\hline
\end{tabular}




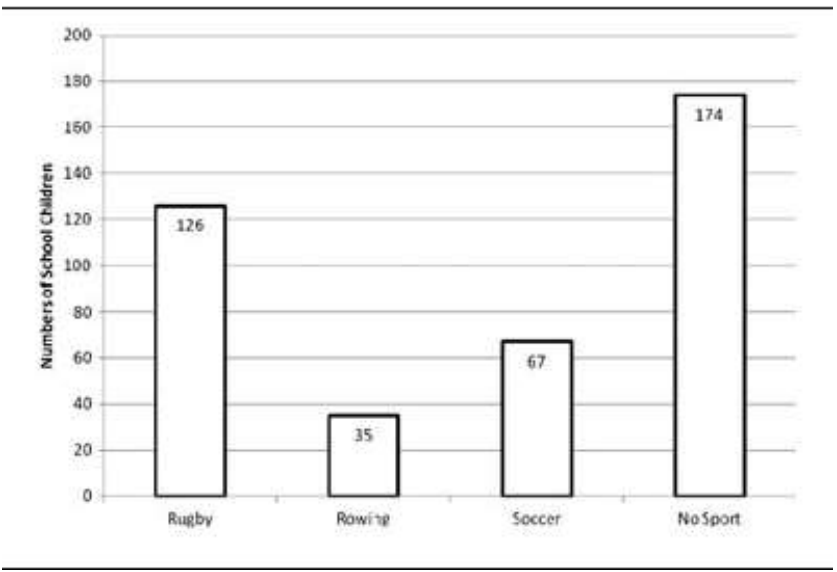

Figure 1. Overall Numbers of Schoolchildren and Sports Participation: 2014-2017

Children were assigned to a category following discussion with teaching staff at the school, coaching staff of the particular sports, consultation of past school newsletters or other school publications, and verbal contact with the individual student or student peers. Involvement in a particular sport was based on a student being a member of the school squad at any level during the years studying for their Leaving Certificate (ie, in any of the school teams-first team, second team, etc-if there was more than 1 team).

\section{Data Analysis \\ The data from all 3 years were analyzed using a 1-way ANOVA with 4 levels. Individual group differences were assessed using Bonferroni post hoc analysis. Statistical significance was set at $p<.05$.}

\section{Results}

The largest group over the 3 years of the study was the no sport group, followed by rugby, soccer, and rowing (Figure 1). Interestingly, over the 4 years of the study the numbers of students doing no sport averaged approximately $43 \%$ but the range was $27.5 \%$ (2010) to $55.9 \%$ (2014) as Table 2 shows.

The average Leaving Certificate score from the 4-year study was 420.5 . When aligned with sports par-ticipation, however, rowing was significantly higher than rugby, soccer, and no sport (Figure 2, p $<.05)$, giving a Leaving Certificate points advantage of 73.4 over the next highest category, rugby. The Leaving Certificate scores from rugby, soccer, and no sport were not significantly different to each other. The Leaving Certificate scores from rowing students each year were also consistently higher than from the other categories (Table 2). 
Table 2 Mean (SD) Numbers of Schoolchildren Participating in Sport and Leaving Certificate Score: 2014-2017

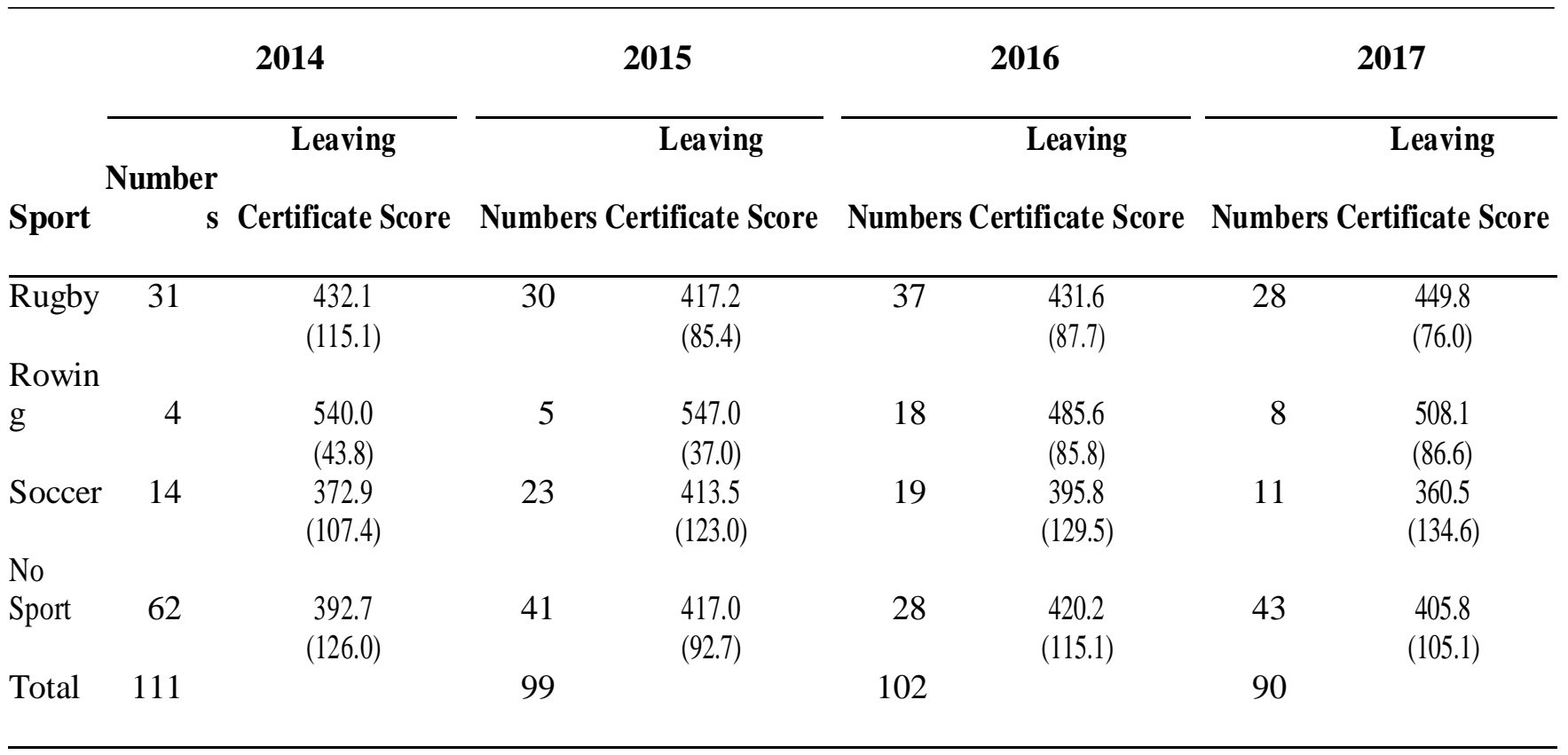

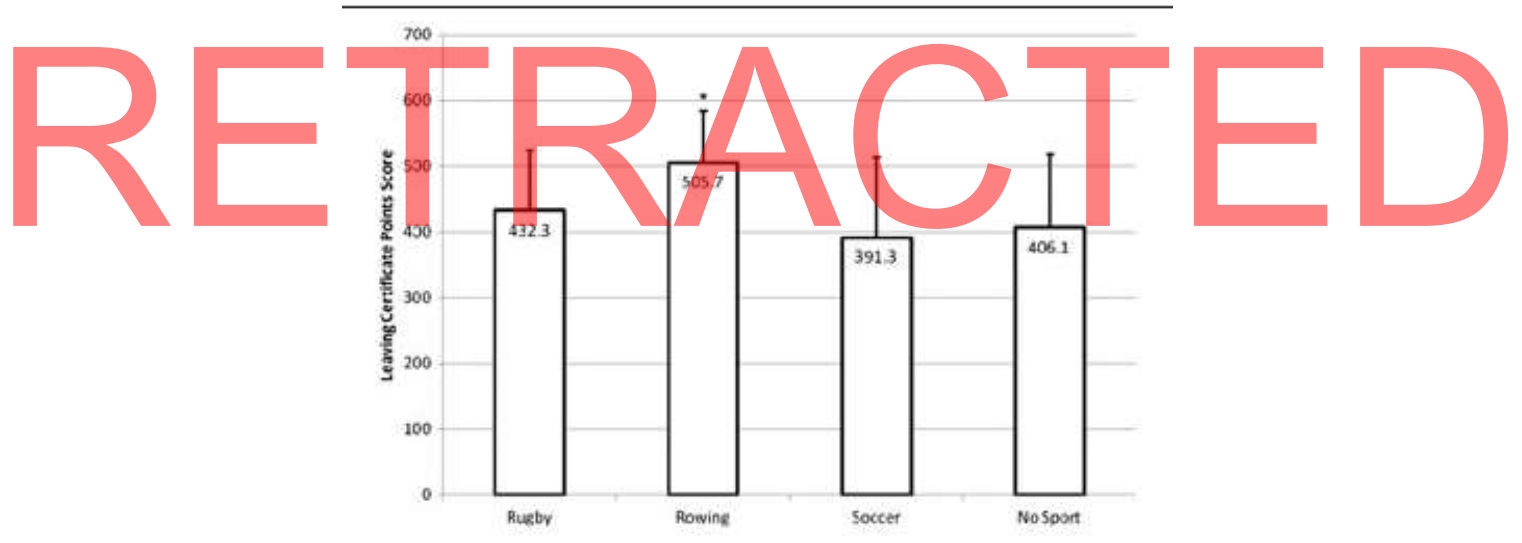

Figure 2. Overall Mean (SD) Leaving Certificate Score From

Schoolchildren and Sporting Participation: 2014-2017*Signif-icant difference, $\mathrm{p}<.05$

Table 3 Students Achieving Higher Than the Average Leaving Certificate Score

\begin{tabular}{|c|c|c|c|}
\hline$\overline{\text { Category }}$ & Rugby Rowing Soccer & Sport & No Spor \\
\hline $\begin{array}{l}\text { Percentage of students } \\
\text { above school mean } \\
\text { Leaving Certificate } \\
\text { score }(420.5)\end{array}$ & $\begin{array}{lll}57.9 \% & 80.0 \% & 47.8 \%\end{array}$ & $58.3 \%$ & $47.1 \%$ \\
\hline $\begin{array}{l}\text { Average Leaving } \\
\text { Certificate scores } \\
\text { (mean (SD)) }\end{array}$ & & $\begin{array}{l}431.5 \\
(106.2)\end{array}$ & $\begin{array}{l}406.1 \\
(111.6)\end{array}$ \\
\hline
\end{tabular}


The numbers of students achieving higher than the school average Leaving Certificate score (420.5) over the study is shown in Table 3. For students participating in any sport, the average Leaving Certificate score was 431.5 points, compared to 406.1 points from students not participating in sport. From students participating in a sport, $58.3 \%$ of them exceeded the school average Leaving Certificate score compared to $47.1 \%$ of students not participating in any sport. Participating in a sport during the Leaving Certificate gave an average Leaving Certificate score benefit of 25.4 points.

Table 4 Sporting Success of the Sports in the Current Study

\section{Sport}

$\begin{array}{ll}\text { Rugby } & \text { Won } 27 \text { Munster Senior Schools Cups and 27 Junior Schools } \\ & \text { Cups. Produced 23 Irish Senior Internationals. } \\ \text { Rowing } & \text { Four national titles and successful annually at regional and } \\ & \text { national regattas at all junior levels. Produced several Irish } \\ & \text { Junior Internationals. } \\ \text { Soccer } & \text { Recent Munster cup winners and semifinalists. Runners-up in } \\ & \text { Munster Schools Cup (under 16 years) }\end{array}$

The school in this study has adopted a strong sports ethos and consistently has done well in local and national competitions. A summary of the sporting success of the 3 sports in this study is shown in Table 4.

\section{Discussion}

Physical Education and School Sport is thought to be beneficial to educational attainment. ${ }^{1}$ The average benefit to the Leaving Certificate scores of 25.4 points from participation in sport supports the "Healthy Body, Healthy Mind" philosophy. The nearly 74-point average benefit that rowing confers to the Leaving Certificate score over the next highest category (rugby) is interesting. To our knowledge, there has been little research over choice of sport among children or the influence of choice of sport on educational attainment. The majority of research in this area relates to the continued participation in sport on leaving school. Research from England shows that adults with a degree-level qualification are 3 times more likely to participate in sports compared to those with no tertiary qualification, ${ }^{11}$ whereas in Ireland, $43 \%$ of people who play sport have a third-level qualification compared to $28 \%$ of the wider population. ${ }^{14}$ The impact of educational attainment on playing sport in Irish adults is consistent across all age groups, so the positive benefit of education on sporting participation lasts a lifetime. ${ }^{14}$ The impact of adult education and low income may have some impact on childhood sporting participation, as there is an indirect link between not playing sport as an adult and having parents who also did not play sport. ${ }^{14}$ Socioeconomic status (SES) has been shown to be related to academic achievement, ${ }^{15}$ and is related to sports participation in adults ${ }^{11}$ but does not influence the physical activity of school children $^{6}$ - presumably as PESS is often a timetabled, compulsory class in the pre-leaving certificate school years. PESS often becomes an optional extracurricular activity in the Leaving Certificate school years in Ireland (age 17-18). Creating an exercise habit in the earlier school years may encourage school children to continue with PESS in their Leaving Certificate school years and allow them to realize the academic benefits shown in this study.

Socioeconomic status was not assessed in the present case study. However, the school participating in the study was 1 of the 56 fee-paying, post-primary schools in Ireland. Fee-paying schools in Ireland are classified as high SES with a high correlation to parental occupation and parental education. ${ }^{16}$ This may suggest that the range of sporting options avail-able to students are greater and may influence the 
results by making more sports accessible to students in their Leaving Certificate years. However, this also provides a greater opportunity to investigate the rela-tionship between choice of school sport and academic achievement. Further research is needed to see if a similar relationship between choice of sport and aca-demic achievement exists in other schools in Ireland and further afield. The range of school sports avail-able is usually determined by the particular school. As mentioned earlier the 3 most common sports in schools in Ireland are team sports, with the most common individual sport, badminton, the fourth most popular school sport. With sport being available mostly as an extracurricular option in the Leaving Certificate years (the situation in this study), participants will have the option to choose to participate in a par-ticular sport or not, rather than participating in a general PESS lesson, when the content is determined by the PE teacher. Children continuing to participate in PESS throughout their Leaving Certificate years perhaps develop a particular personality that may con-fer benefits in academic achievement. Several studies have shown that there is a positive association between sports, extraversion, and conscientiousness. ${ }^{17,18}$ Ath-letes exhibit higher personality scores for extraversion and conscientiousness than non-athletes ${ }^{19}$ and partic-ipation in sport is associated with positive emotions such as feeling energetic, extraverted, and being effi-cient, organized and systematic. ${ }^{18}$ These characteris-tics, while not a prerequisite for sporting participation, will be reinforced and enhanced by continued par-ticipation in sport. Encouraging PESS in early school years may promote these characteristics and encour-age participation in sport throughout the school years and beyond. This study neglected to include any involvement in extra-school sport (sport separate from the school environment). Whereas this has the potential to introduce confounders such as students participating in new sports, the aim of the study was to investigate the role of school sport in academic achievement and the influence of the range of sports offered at a typical fee-paying school in Ireland. Extending this to a wider range of schools would widen the range of sports encountered. Duplicating the school sport in an extra-school context was thought not significantly to affect the findings of this study as it would simply reinforce the influence of participation in sport on academic achievement.

Studies investigating the personality characteristics of high achievers in education suggest key indicators are motivational strategies, self-regulation and self-efficacy. ${ }^{20,21}$ These characteristics of high achievers are consistent with the high levels of conscientiousness and extraversion identified in athletes participating in different sports. Learners who have high levels of conscientiousness show greater motivation levels and are more motivated to learn. ${ }^{22}$ These individuals are more reliable, selfdisciplined, and persevering, leading to greater motivation and self-efficacy. Also, conscientious individuals have a greater tendency for self-deception, ${ }^{23}$ all of which tends to lead to higher achievement levels. Applying this rationale to the current study can perhaps account for the average benefit to the Leaving Certificate score of 25.4 points from those participating in sport.

The most popular sports at school in Ireland are team sports. ${ }^{6}$ However, rowing, the only individual sport available to children in this study produced significantly greater Leaving Certificate scores than the team sports and not participating in any sport. Comparison of personality traits in athletes of individual and team sports showed that athletes of individual sports scored significantly higher on conscientiousness and autonomy and athletes of team sports scored higher in agreeableness and sociotropy. ${ }^{19}$ This perhaps suggests a reason why rowing seems to confer a further advantage on the Leaving Certificate scores compared to rugby and soccer. The higher level of conscientiousness displayed by athletes of individual sports suggests higher levels of motivation to learn and a greater tendency to strive for achievement leading to a greater benefit to academic achievement and Leaving Certificate results.

The Leaving Certificate cycle is a busy time for Irish children. Informal discussion with the children in this study suggested that those who gave up sport in the Leaving Certificate school years did so in order to concentrate on their studies. Students who gave up training for sport often spent less time subsequently on their studies (unpublished observations). The conscientious personality trait 
characteristic of sports participants in general and displayed in greater levels in participants of individual sports in particular may partly account for this. This study suggests that those students who can maintain involvement in a sport benefit both their sport and their Leaving Certificate scores. By having a strong sporting ethos, a school can enhance its reputation in both the sporting field and the educational field. The sporting achievements of the school in this study (Table 4) suggest considerable sporting success nationally in Ireland. Given the significant improvement in the Leaving Certificate scores from students who participated in rowing, perhaps a greater emphasis on individual sports in schools could create a beneficial environment for higher academic achievement.

\section{Limitations}

This study was, to our knowledge, the first study looking into the relationship between choice of school sport and academic achievement. The results and findings are based on sporting participation and Leaving Certificate results from only 1 secondary school in the Republic of Ireland. The findings are consistent over the 4 years of the current study but further research is needed to see if they are consistent in other schools and other areas. The current study is also limited to the sports available at this school. The relatively small number of students involved in rowing may limit the wider application of the results. Further investigation is needed across a range of schools incorporating a range of individual and team sports to support the claims of the current study that the personality characteristics of participants in individual sports can positively influence academic achievement.

\section{Conclusion \\ Our study suggests that participating in extra-curricular school sport whilst studying for Leaving Certificate secondary school-leaver examinations can benefit academic achievement. Furthermore, our results suggest that participating in individual sports confers a further benefit to academic results because of the enhanced positive personality characteristics of conscientiousness and autonomy associated with these sports.}

\section{Implications for School Health}

This study illustrates the impact that school sports can have on academic achievement. The benefits of sport and exercise to health are well recognized. However more academic subjects can often take precedent over PESS during the important final years of secondary school. Encouraging participation in school sport can help promote academic achievement as well as providing an opportunity to achieve health-promoting physical activity. School sport programmes that offer a range of individual and team sports can enhance the benefits that both bring to academic achievement and personality development. This study could have significant impact on the choice of sports offered by schools and the emphasis schools place upon PESS.

\section{Human Subjects Approval Statement}

The study was approved by the Social Research Ethics Committee of University College Cork.

\section{References}

[1] Bailey R, Armour K, Kirk D, Jess M, Pickup I, Sandford R and the BERA Physical Education and Sport Pedagogy Special Interest Group. The educational benefits claimed for physical education and school sport: an academic review. Res Papers Educ. 2009;24(1):1-27.

[2] Pate RR, O’Neill JR, McIver KL. Physical activity and health: does physical education matter? 
Quest. 2017;63:19-35.

[3] Smibert A, Abbot R, Macdonald D, Hogan A, Leong G. School, community, and family working together to address childhood obesity: perceptions from the KOALA lifestyle intervention study. Eur Phys Educ Rev. 2010;16(2):155-170.

[4] Blair SN, Morris JN. Healthy hearts - and the universal benefits of being physically active: physical activity and health. Ann Epidemiol. 2009;19:253-256.

[5] Lunn P, Layte R. Sporting Lives: An Analysis of a Lifetime in Irish

[6] Sport. Dublin: Economic and Social Research Institute, Research Series Number 2; 2014.

[7] Woods CB, Tannehill D, Quinlan A, Moyna N, Walsh J. The Children's Sport Participation and Physical Activity Study (CSPPA). Research Report No 1. Dublin: School of Health and Human Performance, Dublin City University and the Irish Sports Council; 2010.

[8] Morgan K, McGee H, Watson D, et al. SLAN 2007: Survey of Lifestyle, Attitudes \& Nutrition in Ireland. Main Report. Dublin: Department of Health and Children; 2014.

[9] Lissau I, Overpeck MD, Ruan WJ, Due P, Holstein BE, Hedi-ger ML. Body mass index and overweight in adolescents in 13 European countries, Israel and the United States. Arch Pediatr Adoles Med. 2004;158(1):27-33.

[10] Shephard RJ. Curricular physical activity and academic performance. Pediatr Exerc Sci. 1997;9:113-126.

[11] Sallis JF, McKenzie, TL, Kolody, B, Lewis, M, Marshall, S, Rosengard, P. Effects of healthrelated physical education on academic achievement: Project SPARK. Res $Q$ Exercise Sport. 1999;70(2):127-134.

[12]Farrell L, Shields MA. Investigating the economic and demo-graphic determinants of sporting participation in England. J Roy Stat Soc A Stat. 2002;65(2):335-348.

[13] Fahey T, Delaney L, Gannon B. School Children and Sport in

[14] Ireland. Dublin: Economics and Social Research Institute; 2005.

[15] National Council for Curriculum and Assessment Physi-cal Education Draft Syllabus for Consultation. Available at: http://www.ncca.ie/en/Consultations/Senior_Cycle_Physical_ Education/Physical_Education_Syllabus.html. Accessed Octo-ber 1, 2017.

[16]Lunn P. Fair Play? Sport and Social Disadvantage in Ireland. Dublin: The Economic and Social Research Institute; 2007.

[17] White, KR. The relationship between socioeconomic status and academic achievement. Psychol Bull. 1982;91(3):461-481. 